\title{
Effects of Mirror Therapy on the Lower Limb Functionality Hemiparesis after Stroke
}

\author{
Bruno Vieira Cortez ${ }^{1}$, Constância Karyne da Silva Coêlho' ${ }^{1}$, Danylo Rafhael Costa Silva ${ }^{2}$, \\ Maria da Conceição Barros Oliveira², Giselle Borges Vieira Pires de Oliveira ${ }^{3}$, \\ Francisco Mayron de Sousa e Silva1, Éric Heleno Freire Ferreira Frederico", \\ Danúbia da Cunha de Sá-Caputo4, Mario Bernardo-Filho4, Janaína de Moraes Silva ${ }^{3}$
}

\footnotetext{
${ }^{1}$ Departamento de Fisioterapia, Faculdade Maurício de Nassau, Teresina, Brasil

${ }^{2}$ Pós-graduação da Rede Nordeste de Biotecnologia da Universidade Federal do Piauí, Universidade Federal do Piauí, Teresina, Brasil ${ }^{3}$ Departamento de Fisioterapia, Universidade Estadual do Piauí, Teresina, Brasil

${ }^{4}$ Laboratório de Vibrações Mecânicas e Práticas Integrativas e Complementares, Universidade do Estado do Rio de Janeiro, Rio de Janeiro, Brasil

Email: bruno_cortez14@hotmail.com,c.karynecoelho@hotmail.com,danylorafhael@hotmail.com, mariah.da.conceicao@hotmail.com, gigivieira@yahoo.com.br, mayronfisio@hotmail.com, ericfrederico@msn.com, dradanubia@gmail.com, bernardofilhom@gmail.com, fisiojanainams@gmail.com
}

How to cite this paper: Cortez, B.V., Coêlho, C.K.S., Silva, D.R.C., Oliveira, M.C.B., Oliveira, G.B.V.P., Sousa e Silva, F.M., Frederico, É.H.F.F., Sá-Caputo, D.C., Bernardo-Filho, M. and Silva, J.M. (2016) Effects of Mirror Therapy on the Lower Limb Functionality Hemiparesis after Stroke. Health, 8, 14421452.

http://dx.doi.org/10.4236/health.2016.814144

Received: October 1, 2016

Accepted: November 7, 2016

Published: November 10, 2016

Copyright (c) 2016 by authors and Scientific Research Publishing Inc. This work is licensed under the Creative Commons Attribution International License (CC BY 4.0).

http://creativecommons.org/licenses/by/4.0/ c) $\underset{\mathrm{EY}}{\text { (i) Open Access }}$

\begin{abstract}
Introduction: Mental exercise using the mirror therapy (MT) improves the retention of newly acquired skills and the performance of sequential motor skills in subjects with post-stroke hemiparesis. Objectives: The study aimed to analyze the mirror therapy effect on the range of motion and the lower limb functionality in poststroke hemiparesis subjects. Materials and Methods: Eleven participants with hemiparesis in the lower limb were subjected to the 10 sessions of a MT protocol. The interventions were three times per week per 30 minutes each day. Evaluation of active and passive ankle goniometry (dorsiflexion and eversion movements); Ascent and Descent Ladder Rate (ADLR); Time Up and Go test (TUG test); EFEI scale; and FAAM scale were performed. The data were collected before and after the intervention using MT, and then statistically compared. Results: The MT improved significantly $(p<0.01)$ the range of motion of the paretic lower limb both evaluated by active and passive ankle goniometry. An increase in the speed of gait and other functional tasks related to the paretic lower limbs were found through the TUG and ADLR tests. It also demonstrated a positive influence on the functionality of the paretic lower limb motor control through the analysis of the scores in the FAAM and EFEI scales. Conclusion: It is concluded that the MT therapy can help the patients with post-stroke hemiparesis in the improvement of several functions. Probably, the mirror therapy would aid in the repair of the injuries in the cortical areas.
\end{abstract}




\section{Keywords}

Mirror Therapy, Stroke, Hemiparesis, Visual Feedback, Functionality

\section{Introduction}

Stroke is defined as a focal and acute neurological deficit, lasting more than 24 hours, due to a vascular injury. The consequences are related to its location and extension. Among the causes, there is the obstruction or rupture of a cerebral artery, leading to the ischemic or hemorrhagic strokes, respectively [1] [2] [3].

As consequences of the stroke, there are several deficits, such as cognitive, sensory, perception, language and motor. They can be temporary or permanent, according to the affected region, level of injury and the individual capability. They can interfere directly on the functional capacity of the affected individuals [4] [5] [6] [7].

The chance of a person to have a stroke approximately doubles for each decade of life after 55 years old and it occupies an important position among the elderly. The worldwide prevalence of stroke in the general population is estimated from $0.5 \%$ to $0.7 \%$ [8]. It is suggested that, without appropriated intervention, the number of deaths due to the stroke will increase to 6.3 million by 2015 and 7.8 million in 2030 [9].

Neurological rehabilitation programs based on suitable motor control models and on motor learning theories have shown positive responses in the functional recovery of the affected lower limb [10]. Trevisan et al. [11] have suggested a procedure based on the mirror therapy (MT). This technique aims to accelerate the motor recovery of the lower paretic member, integrating sensory stimuli to motor responses, remodeling cortical connections and promoting changes in areas with cortical representation.

The general principles of the MT consist of a strategy involving "motor copy", with an induction of the use of the paretic limb through the mobilization of the healthy limb using an external feedback using the mirror, and an internal feedback through the mental practice of functional activities [11] [12].

Mirror therapy is an inexpensive, safe and useful feature. It is currently used for the treatment of post-stroke hemiparesis in order to mitigate the sensorimotor deficits and to accelerate the functional rehabilitation of the affected limb [13]-[18]. Amasyali and Yaliman [19] have reported improvements of functions of the upper extremity (hand skills) in patients with ischemic stroke.

Due to the relevance of the rehabilitaion of the patients with stroke, this study aimed to evaluate the mirror therapy on the range of motion and functionality of the lower limb in subjects with post-stroke hemiparesis.

\section{Materials and Methods}

\subsection{Ethics Approach and the Selection of Subjects}

Eleven subjects with post-stroke hemiparesis were included in the study and they were 
outpatients of the Clínica Escola de Fisioterapia, Faculdade Maurício de Nassau, Teresina city, Piauí, Brazil. They were informed about the study and they decided to participate in it. All subjects signed a consent and informed form to participate in the study before to start the evaluation.

This study was approved by the Ethics Committee of the Hospital São Marcos Teresina city, Piauí, Brazil under the number 973598.

\subsection{Inclusion and Exclusion Criteria}

Considering the inclusion criteria, the study included individuals (i) with both sexes, (ii) with age over 55 years old, (iii) spasticity ranked $1,1+$ and 2 according to the Modified Ashworth Scale [20], (iv) absence of cognitive impairment, (v) stroke episode (hemorrhagic or ischemic) for at least 6 months and (vi) that can walk without ortheses.

Considering the exclusion criteria, subjects were excluded if they had (a) more than 80 years old, (b) signals of visual impairment, (c) clinical evaluation revealed existence of multiple brain lesions and cardiorespiratory changes, (d) previous lesions in the affected limb before the stroke and (e) refused to sign the consent and informed form.

\subsection{Intervention}

All the participants were in a single intervention group. The intervention and data collection were carried out by a single evaluator and according to the availability of the patients, according to a sequence of three sessions per week, in a total of ten sessions.

In the intervention, the subject was asked to use of the paretic limb through the mobilization of the healthy limb in front of a mirror, and an internal feedback through the mental practice of functional activities [11] [12]. In the protocol of the MT involving the lower limbs, there were three sets of ten repetitions for each movement of dorsiflexion and eversion ankle in the sitting position. A rectangular mirror $(50 \mathrm{~cm}$ of wide and $91 \mathrm{~cm}$ of length) was positioned with reference to the sagittal subject's line. In this condition, the healthy lower limb remained in visual field of the subject and the affected lower limb covered by the reflecting object. Subjects were instructed to observe the healthy limb through the reflection of the mirror and perform the same activities with the paretic limb.

\subsection{Evaluations}

All the subjects were evaluated before and after the intervention, as (i) active and passive Goniometry ankle (dorsiflexion and eversion movements) [21], (ii) time up and go test [22], (iii) cadence test in climbing up and down a stair [23], (iv) filling the questionnaire Foot and Ankle Ability Measure (FAAM) [24] and Lower Extremity Functional scale (EFEI) [25].

The FAAM questionnaire is an instrument composed of items for assessing the physical performance of individuals with musculoskeletal disorders of the leg, ankle and foot. The original version of the FAAM is divided into two areas, one subscale of 
Activities of Daily Living (ADLs), consisting of 21 items and other Sport subscale consisting of 8 items. These scales are scored separately and generated three scores, one for each scale and the total score of the instrument. Each item is scored on a Likert scale, ranging from 0 (unable to do) to 4 (any difficulty). Therefore, the maximum score on ADL subscale are 84 points and subscale Sport are 32. For each item there is the option called "Not applicable (N/A)". This option is not scored and thus is not considered in the final calculation of the score. The values obtained are transformed into percentage, and $100 \%$ indicates the highest level of functionality [26]. The FAAM is valid, reliable and responsive to changes in the health status of individuals [27]. In this experimental study, it will be considered only the sub-scale of activities of daily living (ADL), as a criterion for specific functional assessment of the ankle and foot complex.

The EFEI was developed based on the criteria established by the function model and disability prepared by the World Health Organization (WHO). It is used in individuals with orthopedic disorders in the lower limbs, especially knee and ankle, and it is considered a specific instrument for these body segments. It consists of 20 items, each with a maximum score of four points, with a maximum score of 80 points, which means a normal functional state, and a minimum of nine points. The questionnaire can be self-administered, with an approximate time of 2 minutes to complete all the items [28].

\subsection{Statistical Analysis}

Data processing and statistical analysis were performed using SPSS software, version 19.0. Data were statistically analyzed by Pearson's test, with statistical significance level of $95 \%(p<0.05)$.

\section{Results}

Eleven participants (four female and seven male) with $64 \pm 9.74$ years old participated in this study.

Figure 1 shows the comparative data related to the active and passive goniometry [21] of the dorsiflexion and eversion movements of the hemiparetic ankle before and after the interventions with mirror therapy. It is possible to verify a significant difference in the data before and after the intervention. The MT seems to generate a better improvement to the active goniometry $(p<0.01)$.

Figure 2 shows the comparative data of the Time Up and Go Test [22] before and after the intervention of the MT. It is verified a significant $(p<0.01)$ improvement (reduction) of the time to perform the Time Up and Go Test after the MT.

Figure 3 shows the comparative data of the test in climbing up and down a stair [23] before and after the MT. It is found a significant difference $(p<0.01)$ after the MT with a reduction of the time to perform the evaluation.

Figure 4 shows the comparative data of the FAAM scale [24] before and after the MT. It is found a significant improvement $(p<0.01)$ in the score of the questionnaire Foot and Ankle Ability Measure after the MT. 


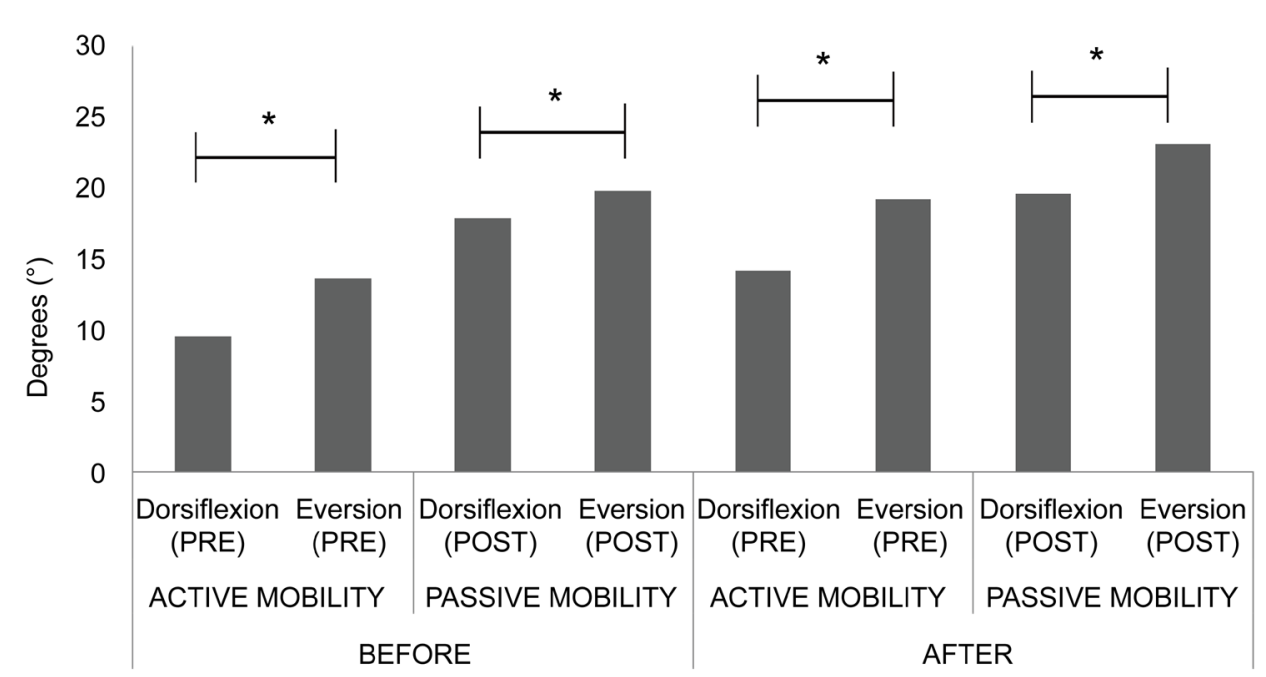

Figure 1. Active and passive goniometry of the dorsiflexion and eversion movements of the hemiparetic ankle before and after the interventions with mirror therapy.
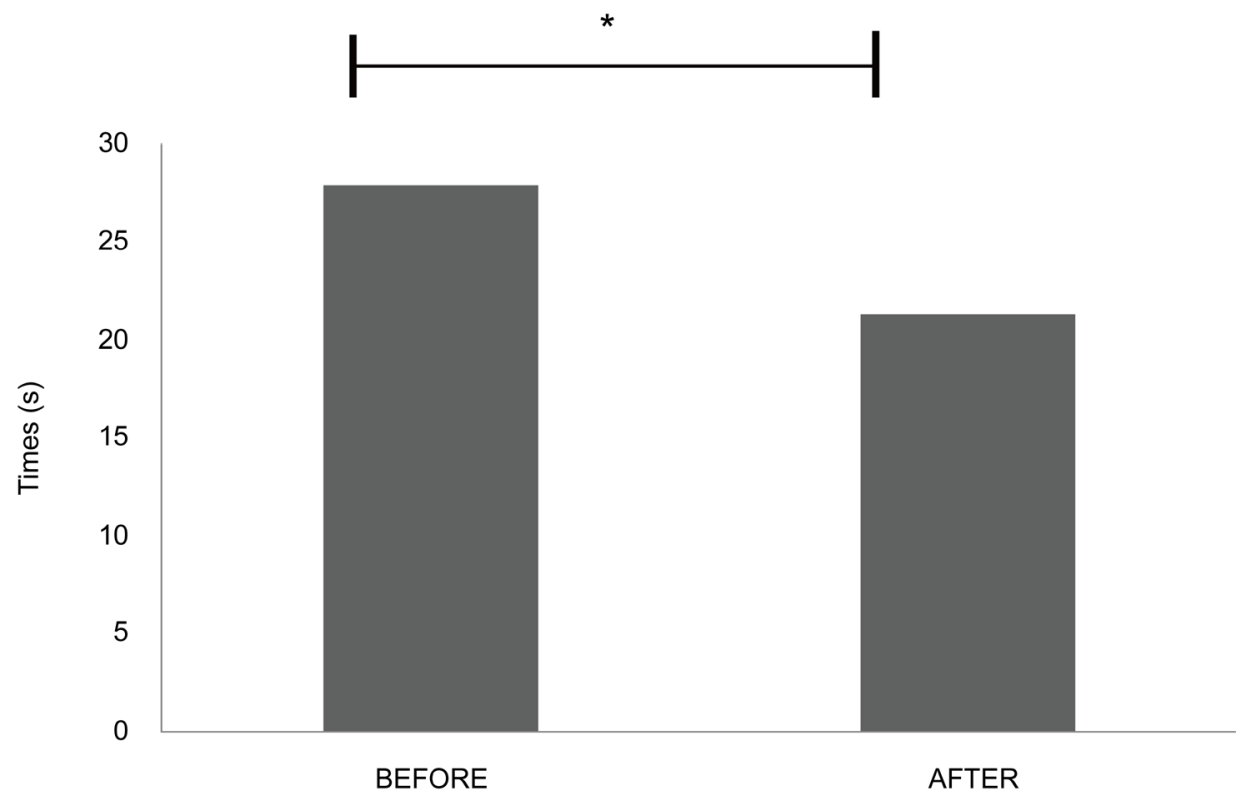

Figure 2. Comparative data of the time up and go test before and after the intervention of the mirror test.

Figure 5 shows the comparative data of the EFEI scale [25] before and after the MT. It is found a significant improvement $(p<0.01)$ in the Lower Extremity Functional scale after the MT.

\section{Discussion}

As the results of measurements of the range of motion, mirror therapy provided significantly increase the amplitude of the lower limb movements paretic, dorsiflexion and eversion (Figure 1). This finding could be associated with the increase of the muscle strength, as described in a case study of Ramachandran; Altschuler [29] found satisfactory 

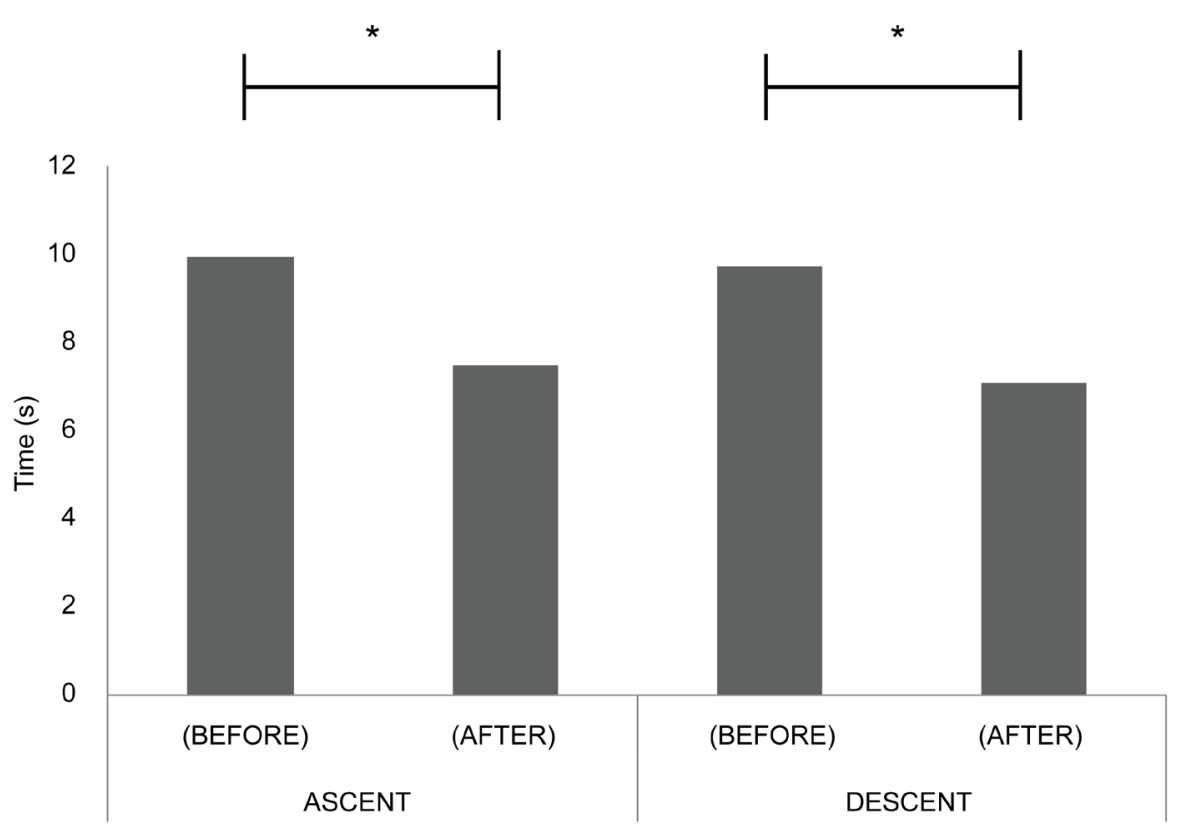

Figure 3. Comparative data of the test in climbing up and down a stair before and after the mirror test.
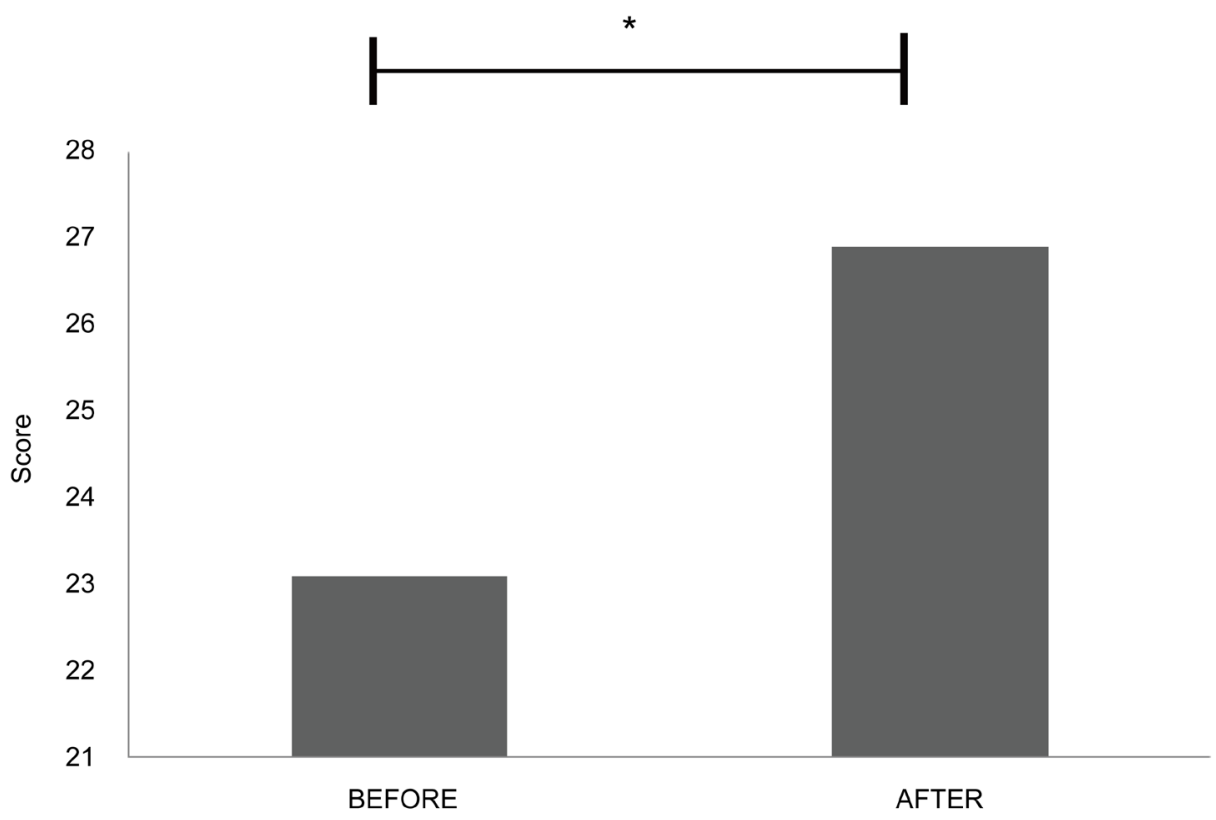

Figure 4. Comparative data of the FAAM scale before and after the mirror test.

results within the muscle strength and range of motion of the paretic limb after application of the mirror therapy. This would related to the mental performance of motor images, in which there was increased attention and concentration, providing developments in the planning and execution of the tasks proposed and information processing capacity. This would involve greater repetitiveness of training and better improvement of the motor performance [29]. 

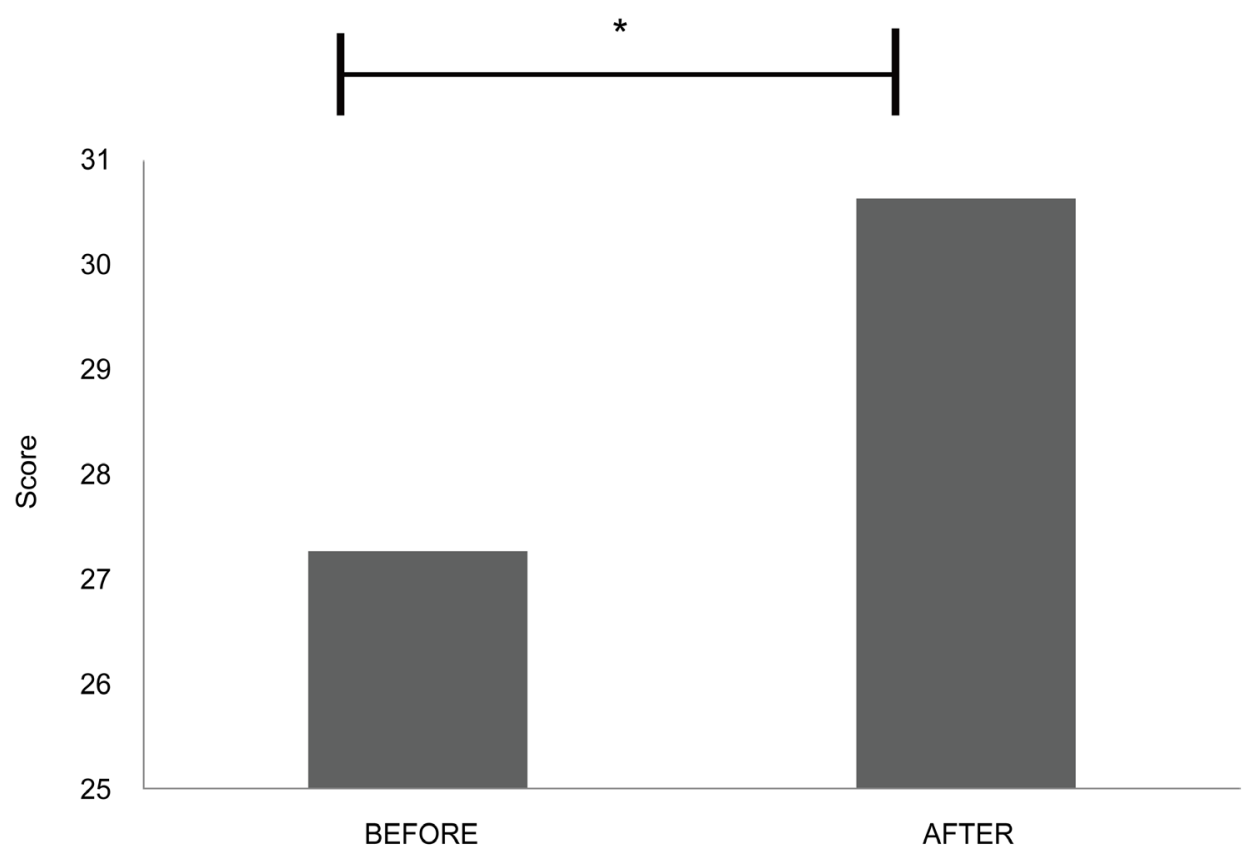

Figure 5. Comparative data of the EFEI scale before and after the mirror test.

Rocha, [30] has reported that two participants with post-stroke hemiparesis chronic, with important difficulty to perform the dorsiflexion movements of the ankle, which underwent a 10 minutes-intervention with the mirror therapy. The physical evaluation post-treatment shows that the participants still had gait with hemiparetic characteristics and with difficulty to perform dorsiflexion movements of the paretic ankle. However, the evaluation of the images through the software Postural Assessment (SAPO) indicated that that both participants were able to increase the hemiparetic ankle dorsiflexion. In addition, Rocha [30] emphasized that a therapeutic approach to long-term intervention and with greater intensity and frequency of training is necessary.

Regarding the gait functionality, it was verified that after 10 sessions with the mirror therapy, the average post-treatment time to perform the Time Up and Go Test and Rate of Climb and Ladder Descent decreased in comparison with the values before the intervention. It was observed that the intervention with the mirror therapy led to an improvement of the paretic lower limb function, both in reducing the time to perform the tests (Figure 2 and Figure 3). These findings are in agreement with Pauline; Shepherd [31] that have found (i) the reduction of the time to perform the TUG test, (ii) increase of the speed to do simple and advanced activities involving the functions of the lower limbs post-stroke paretic. It was suggested that all mental activities were part of a weekly routine, and kinesthetic information provided by the generation of the images were more easily processed when the participant was more familiar with the movement, making it more muscle strength, balance and coordination, as also described by Iestwaart et al. [32]. However, in a clinical study with 20 participants with lower limb paretic after stroke submitted to the mirror therapy for thirty minutes, five days a week for four weeks and in combination with conventional physical therapy treatment, 
showed no improvement in the time to the gait performance [33]. Colomer et al. [34] have also described that the mirror therapy in chronic stroke survivors with severely impaired upper-limb function provides a limited but positive effect on light touch sensitivity while providing similar motor improvement.

The results of this current study demonstrate positive influence of mirror therapy on functionality and limb motor control lower post-stroke paretic, through the evaluation of FAAM (Figure 4) and EFEI (Figure 5) scales. There were significant improvements in the scores after the intervention related to their daily living activities and functional capacity of the lower limb. It is suggested that the functional improvement occurs due to visual stimuli with the mirror that are able to enhance the neural plasticity to repair functions that were damaged by the stroke [35] [36]. These findings are supported by Souza; Rangel and Silva [37] that reported the maintenance of the motor and sensory gains and improvement of the functionality, even over six months after the mirror therapy in post-stroke paretic limb. Furthermore, study using electromyography analyzes demonstrate the mirror therapy is capable in promoting activation of cortical areas responsible for proprioception, vision and motor control, generating activation of a network mirror neurons and stimulating neuronal plasticity. Putting together all the findings, it is possible to suggest and to justify the motor recovery and improvement of the functionality of participants with post-stroke hemiparesis [38]. Gaspar et al. [39] have suggested that the mirror therapy could be used as a resource for rehabilitation through mental practice of functional activities. Moreover, it is reported that the mirror therapy when combined with kinesitherapy is more effective in hemiparetic patients than is used alone.

\section{Conclusion}

It is concluded that the mirror therapy can help the patients with post-stroke hemiparesis in the improvement of several functions. Probably, the mirror therapy would aid in the repair of the injuries in the cortical areas.

\section{References}

[1] Akbarzadeh Baghban, A., Ahmadi Gooraji, S., Kavousi, A. and Mirzakhani Araghi, N. (2015) Application of Hurdle Model with Random Effects for Evaluating the Balance Improvement in Stroke Patients. Medical Journal of the Islamic Republic of Iran, 29, 244.

[2] Billinger, S.A., Arena, R., Bernhardt, J., Eng, J.J., Franklin, B.A., Johnson, C.M., et al. (2014) Physical Activity and Exercise Recommendations for Stroke Survivors: A Statement for Healthcare Professionals from the American Heart Association/American Stroke Association. Stroke, 45, 2532-2553. http://dx.doi.org/10.1161/STR.0000000000000022

[3] Joseph, C. and Rhoda, A. (2013) Activity Limitations and Factors Influencing Functional Outcome of Patients with Stroke Following Rehabilitation at a Specialised Facility in the Western Cape. African Health Sciences, 13, 646-654. http://dx.doi.org/10.4314/ahs.v13i3.18

[4] Faria-Fortini, I., Michaelsen, S.M., Cassiano, J.G. and Teixeira-Salmela, L.F. (2011) Upper Extremity Function in Stroke Subjects: Relationships between the International Classification of Functioning, Disability, and Health Domains. Journal of Hand Therapy, 24, 257264. http://dx.doi.org/10.1016/j.jht.2011.01.002 
[5] Naghdi, S., Ansari, N.N., Rastgoo, M., Forogh, B., Jalaie, S. and Olyaei, G. (2015) A Pilot Study on the Effects of Low Frequency Repetitive Transcranial Magnetic Stimulation on Lower Extremity Spasticity and Motor Neuron Excitability in Patients after Stroke. Journal of Bodywork and Movement Therapies, 19, 616-623.

http://dx.doi.org/10.1016/j.jbmt.2014.10.001

[6] Li, L., Yiin, G.S., Geraghty, O.C., Schulz, U.G., Kuker, W., Mehta, Z. and Rothwell, P.M. (2015) Oxford Vascular Study. Incidence, Outcome, Risk Factors, and Long-Term Prognosis of Cryptogenic Transient Ischaemic Attack and Ischaemic Stroke: A Population-Based Study. Lancet Neurology, 14, 903-913. http://dx.doi.org/10.1016/S1474-4422(15)00132-5

[7] Hayashi, T., Kato, Y., Fukuoka, T., Deguchi, I., Maruyama, H., Horiuchi, Y., Sano, H., Nagamine, Y., Mizuno, S. and Tanahashi, N. (2015) Clinical Features of Ischemic Stroke during Treatment with Dabigatran: An Association between Decreased Severity and a Favorable Prognosis. Internal Medicine, 54, 2433-2437. http://dx.doi.org/10.2169/internalmedicine.54.4948

[8] Giles, M.F. and Rothwell, P.M. (2008) Measuring the Prevalence of Stroke. Neuroepidemiology, 30, 205-206. http://dx.doi.org/10.1159/000126913

[9] Bonita, R. and Beaglehole, R. (2007) Stroke Prevention in Poor Countries: Time for Action. Stroke, 38, 2871-2872. http://dx.doi.org/10.1161/STROKEAHA.107.504589

[10] Brunetti, M., Morkisch, N., Fritzsch, C., Mehnert, J., Steinbrink, J., Niedeggen, M. and Dohle, C. (2015) Potential Determinants of Efficacy of Mirror Therapy in Stroke PatientsA Pilot Study. Restorative Neurology and Neuroscience, 33, 421-434. http://dx.doi.org/10.3233/RNN-140421

[11] Trevisan, C.M., Trevisan, M.E., Oliveira, R.M., Mota, C.B. and Pratesi, R. (2007) Reabilitação da hemiparesia pós-acidente vascular encefálico com mirror visual feedback. Fisioteria Brasil, 8, 452-454.

[12] Trevisan, C.M. and Trintinaglia, V. (2010) Efeito das terapias associadas de imagem motora e de movimento induzido por restrição na hemiparesia crônica: Estudo de caso. Fisioteria e Pesquisa, 17, 1809-2950. http://dx.doi.org/10.1590/s1809-29502010000300014

[13] Harmsen, W.J., Bussmann, J.B., Selles, R.W., Hurkmans, H.L. and Ribbers, G.M. (2015) Mirror Therapy-Based Action Observation Protocol to Improve Motor Learning after Stroke. Neurorehabilitation and Neural Repair, 29, 509-516. http://dx.doi.org/10.1177/1545968314558598

[14] Souza, W.C., Range, M.C.M. and Silva, E.B. (2012) Mirror Visual Feedback in Motor and Functional Recovery Post Stroke. Revista Neurociências, 20, 254-259.

http://dx.doi.org/10.4181/RNC.2012.20.685.6p

[15] Ramachandran, V.S. and Altschuler, E.L. (2009) The Use of Visual Feedback, in Particular Mirror Visual Feedback, in Restoring Brain Function. Brain, 132, 693-710. http://dx.doi.org/10.1093/brain/awp135

[16] Kim, J.H. and Lee, B.H. (2015) Mirror Therapy Combined with Biofeedback Functional Electrical Stimulation for Motor Recovery of Upper Extremities After Stroke: A Pilot Randomized Controlled Trial. Occupational Therapy International, 22, 51-60. http://dx.doi.org/10.1002/oti.1384

[17] Nojima, I., Mima, T., Koganemaru, S., Thabit, M.N., Fukuyama, H. and Kawamata, T. (2012) Human Motor Plasticity Induced by Mirror Visual Feedback. Journal of Neuroscience, 32, 1293-300. http://dx.doi.org/10.1523/JNEUROSCI.5364-11.2012

[18] Lee, H.M., Li, P.C. and Fan, S.C. (2015) Delayed Mirror Visual Feedback Presented Using a Novel Mirror Therapy System Enhances Cortical Activation in Healthy Adults. Journal of NeuroEngineering and Rehabilitation, 12, 56. http://dx.doi.org/10.1186/s12984-015-0053-1 
[19] Amasyali, S.Y. and Yaliman, A. (2016) Comparison of the Effects of Mirror Therapy and Electromyography-Triggered Neuromuscular Stimulation on Hand Functions in Stroke Patients: A Pilot Study. International Journal of Rehabilitation Research, 39, 302-307. http://dx.doi.org/10.1097/MRR.0000000000000186

[20] Bohannon, R.W. and Smith, M.B. (1987) Interrater Reliability of a Modified Ashworth Scale of Muscle Spasticity. Physical Therapy, 67, 206-207.

[21] Magee, D.J. (2002) Princípios e Conceitos In: Magee, D.J., Ed., Disfunção Musculoesquelética, 3rd Edition, Manole, São Paulo, 1-54.

[22] Podsiadlo, D. and Richardson, S. (1991) The Timed "Up \& Go": A Test of Basic Functional Mobility for Frail Elderly Persons. Journal of the American Geriatrics Society, 39, 142-148. http://dx.doi.org/10.1111/j.1532-5415.1991.tb01616.x

[23] Olney, S., Elkin, N. and Lowe, P. (1979) An Ambulation Profile for Clinical Gait Evaluation. Physiotherapy Canada, 31, 85-90.

[24] Martin, R.L., Irrgang, J.J., Burdett, R.G., Conti, S.F. and Van Swearingen, J.M. (2005) Evidence of Validity for the Foot and Ankle Ability Measure (FAAM). Foot \& Ankle International, 26, 968-983.

[25] Binkley, J.M., Stratford, P.W., Lott, S.A. and Riddle, D.L. (1999) The Lower Extremity Functional Scale (LEFS): Scale Development, Measurement Properties, and Clinical Application. North American Orthopaedic Rehabilitation Research Network. Physical Therapy, 79, 371-383.

[26] Garcia, C.R, Martin, R.L. and Drouin, J.M. (2008) Validity of the Foot and Ankle Ability Measure in Athletes with Chronic Ankle Instability. Journal of Athletic Training, 43, 179183. http://dx.doi.org/10.4085/1062-6050-43.2.179

[27] Moreira, T.S., Sabino, G.S. and Resende, M.A. (2010) Instrumentos clínicos de avaliação funcional do tornozelo: Revisão sistemática. Fisioterapia e Pesquisa, 17, 88-93. http://dx.doi.org/10.1590/S1809-29502010000100016

[28] Ross, S.E., Guskiewicz, K.M., Gross, M.T. and Yu, B. (2008) Assessment Tools for identifying Functional Limitations Associated with Functional Ankle Instability. Journal of Athletic Training, 43, 44-50. http://dx.doi.org/10.4085/1062-6050-43.1.44

[29] Ramachandran, V.S. and Altschuler, E.L. (2009) The Use of Visual Feedback, in Particular Mirror Visual Feedback, in Restoring Brain Function. Brain, 132, 1693-1710.

http://dx.doi.org/10.1093/brain/awp135

[30] Rocha, A.S. (2009) Efeito da restrição do membro inferior não afetado e altura do assento sobre o desempenho motor de hemiparéticos durante o movimento de sentado para de pé. 118 f. Msc-UDESC, Florianópolis,.

[31] Paulino, R.H. and Pastor, F.H.C. (2014) Feedback Visual Com Espelho Em Membro Inferior Parético Após Acidente Vascular Encefálico: Estudo De Casos. Revista Inspirar Movimento \& Saúde, 6, 1-5.

[32] Ietswaart, M., Johnston, M., Dijkerman, H.C., Scott, C.L., Joice, A.S. and Hamilton, S. (2006) Recovery of Hand Function through Mental Practice: A Study Protocol. BMC Neurology, 6, 39. http://dx.doi.org/10.1186/1471-2377-6-39

[33] Sutbeyaz, S., Yavuzer, G., Sezer, N. and Koseoglu, F. (2007) Mirror Therapy Enhances Lower-Extremity Motor Recovery and Motor Functioning after Stroke: A Randomized Controlled Trial. Archives of Physical Medicine and Rehabilitation, 88, 555-559. http://dx.doi.org/10.1016/j.apmr.2007.02.034

[34] Colomer, C., Noé, E. and Llorens, R. (2016) Mirror Therapy in Chronic Stroke Survivors with Severely Impaired Upper Limb Function: A Randomized Controlled Trial. European 
Journal of Physical and Rehabilitation Medicine, 52, 271-278.

[35] Ramachandran, V.S. (2005) Plasticity and Functional Recovery in Neurology. Clinical Medicine, 5, 368-373. http://dx.doi.org/10.7861/clinmedicine.5-4-368

[36] Ji, S.G. and Kim, M.K. (2015) The Effects of Mirror Therapy on the Gait of Subacute Stroke Patients: A Randomized Controlled Trial. Clinical Rehabilitation, 29, 348-354. http://dx.doi.org/10.1177/0269215514542356

[37] Souza, W.C., Rangel, M.C.M. and Silva, E.B. (2012) Mirror visual feedback na recuperação motora e funcional da mão após acidente vascular cerebral. Revista Neurociências, 20, 254259. http://dx.doi.org/10.4181/RNC.2012.20.685.6p

[38] Nojima, I., Mima, T., Koganemaru, S., Thabit, M.N., Fukuyama, H. and Kawamata, T. (2012) Human Motor Plasticity Induced by Mirror Visual Feedback. Journal of Neuroscience, 32, 1293-1300. http://dx.doi.org/10.1523/JNEUROSCI.5364-11.2012

[39] Gaspar, B.E., Hotta, T.T.H. and Souza, L.A.P.S. (2011) Prática mental na reabilitação de membro superior após acidente vascular encefálico-Casos clínicos. Conscientia e Saúde, 10, 319-325. http://dx.doi.org/10.5585/conssaude.v10i2.2483

Submit or recommend next manuscript to SCIRP and we will provide best service for you:

Accepting pre-submission inquiries through Email, Facebook, LinkedIn, Twitter, etc. A wide selection of journals (inclusive of 9 subjects, more than 200 journals)

Providing 24-hour high-quality service

User-friendly online submission system

Fair and swift peer-review system

Efficient typesetting and proofreading procedure

Display of the result of downloads and visits, as well as the number of cited articles Maximum dissemination of your research work

Submit your manuscript at: http://papersubmission.scirp.org/

Or contact health@scirp.org 